\title{
A panel of clinical and neuropathological features of cerebrovascular disease through the novel neuroimaging methods
}

\author{
Gillberto Sousa Alves ${ }^{1}$, Luiza de Amorim de Carvalho' ${ }^{1}$, Felipe Kenji Sudo ${ }^{2,3}$, \\ Lucas Briand ${ }^{1}$, Jerson Laks ${ }^{4,5}$, Eliasz Engelhardt ${ }^{6}$
}

\begin{abstract}
The last decade has witnessed substantial progress in acquiring diagnostic biomarkers for the diagnostic workup of cerebrovascular disease (CVD). Advanced neuroimaging methods not only provide a strategic contribution for the differential diagnosis of vascular dementia (VaD) and vascular cognitive impairment (VCl), but also help elucidate the pathophysiological mechanisms ultimately leading to small vessel disease (SVD) throughout its course. Objective: In this review, the novel imaging methods, both structural and metabolic, were summarized and their impact on the diagnostic workup of age-related CVD was analysed. Methods: An electronic search between January 2010 and 2017 was carried out on PubMed/MEDLINE, Institute for Scientific Information Web of Knowledge and EMBASE. Results: The use of full functional multimodality in simultaneous Magnetic Resonance (MR)/Positron emission tomography (PET) may potentially improve the clinical characterization of $\mathrm{VCI}-\mathrm{VaD}$; for structural imaging, $\mathrm{MRI}$ at 3.0 $\mathrm{T}$ enables higher-resolution scanning with greater imaging matrices, thinner slices and more detail on the anatomical structure of vascular lesions. Conclusion: Although the importance of most of these techniques in the clinical setting has yet to be recognized, there is great expectancy in achieving earlier and more refined therapeutic interventions for the effective management of $\mathrm{VCl}-\mathrm{VaD}$. Key words: neuroimaging, vascular, PET, MRI, diffusion tensor imaging, DTI, novel methods.
\end{abstract}

\section{UM PAINEL DE CARACTERÍSTICAS CLÍNICAS E NEUROPATOLÓGICAS DA DOENÇA CEREBROVASCULAR ATRAVÉS DOS NOVOS MÉTODOS DE NEUROIMAGEM}

RESUMO. A última década vem testemunhando avanços substanciais na aquisição de marcadores biológicos para 0 diagnóstico da doença cerebrovascular (DCV). Os métodos de neuroimagem avançados não apenas fornecem uma contribuição estratégica para o diagnóstico diferencial do comprometimento cognitivo vascular (VCl) e demência vascular $(\mathrm{VaD})$, mas contribuem substancialmente na elucidação dos mecanismos fisiopatológicos relacionados à doença de vasos pequenos (SVD) e sua progressão clínica. Objetivo: Nesta revisão, métodos de imagem estruturais e metabólicos foram descritos e sua importância diagnóstica analisada, particularmente na investigação da CVD relacionada ao envelhecimento. Métodos: uma pesquisa eletrônica de janeiro de 2010 a 2017 foi realizada através do PubMed/ MEDLINE, do Instituto de Informação Científica Web of Knowledge e da EMBASE. Resultados: 0 emprego de estudos de multimodalidade plenamente funcional com Ressonância Magnética (MR)/ Tomografia por Emissão de Pósitrons (PET) representa uma janela para a caracterização clínica mais detalhada da VCI-VaD; com relação à neuroimagem estrutural, a ressonância magnética em 3,0 T vem permitindo varreduras com maior resolução e matrizes de imagem mais elevadas, cortes mais delgados e maior detalhamento anatômico das lesões vasculares. Conclusão: Embora a importância da maior parte dessas técnicas no cenário clínico aguarde reconhecimento, há uma grande expectativa de que 0 seu uso favoreça intervenções terapêuticas progressivamente mais precoces e refinadas para o gerenciamento efetivo do VCl-VaD.

Palavras-chave: neuroimagem, vascular, PET, ressonância magnética, imagem de tensor de difusão, DTI, métodos inovadores.

This study was conducted at the Departamento de Medicina Interna, Universidade Federal do Ceará, CE, Brazil.

'Departamento de Medicina Interna, Universidade Federal do Ceará, CE, Brazil. "²Departamento de Psicologia, Pontifícia Universidade Católica do Rio de Janeiro, RJ, Brazil. ${ }^{3}$ Instituto D'Or de Ensino e Pesquisa, Rio de Janeiro, RJ, Brazil. ${ }^{4}$ Instituto de Psiquiatria, Universidade Federal do Rio de Janeiro, RJ, Brazil. ${ }^{5}$ Programa de Pós-Graduação em Biomedicina Translacional (BIOTRANS), Unigranrio, Duque de Caxias, RJ, Brazil. ${ }^{6}$ Setor de Neurologia Cognitiva e do Comportamento, Instituto de Neurologia Deolindo Couto (INDC-CDA/IPUB), Rio de Janeiro, RJ, Brazil.

Gilberto Sousa Alves. Rua Prof. Costa Mendes 1608 / $4^{\circ}$ andar - Fortaleza CE - Brazil. E-mail: gsalves123@hotmail.com

Disclosure: The authors report no conflicts of interest.

Received: October 10, 2017. Accepted in final form November 14, 2017. 


\section{INTRODUCTION}

Tascular cognitive impairment (VCI) is an umbrella term denoting a continuum of behavioral and cognitive deficits associated with cerebrovascular disease (CVD) ${ }^{1-3}$ CVD is estimated to occur in one third of the population, often being recognized as a pathological finding on conventional Magnetic Resonance Imaging (MRI) ${ }^{1,3,4}$ Depending on the site, intensity, and severity, CVD may either cause or contribute to further cognitive impairment. 2,5

Over the last decade, there has been substantial progress in acquiring diagnostic biomarkers for the diagnostic workup of neurodegenerative and vascular disorders. ${ }^{2,6}$ In vivo brain imaging has been applied for several decades to identify brain structural (diseasespecific atrophy) and functional (disease-specific hypometabolism) abnormalities. Advanced neuroimaging methods not only provide a strategic contribution for the differential diagnosis of vascular dementia (VaD), but also help elucidate the pathophysiological mechanisms ultimately leading to small vessel disease (SVD) throughout aging. ${ }^{6}$ One example of the growing importance of structural and functional imaging markers on the diagnostic work up of dementia is that the fifth edition of the DSM (2013) has changed to include a broader definition of cognitive impairment, the neurocognitive disorder. These criteria stress the need to support the etiological diagnosis with neuroimaging markers. ${ }^{6}$

In a relatively short period, particularly in the last 15 years, structural neuroimaging has evolved from a quite artisanal approach - focused on the delimitation of pre-defined Region of interest (ROIs) - to powerful volumetric-based morphometry (VBM) analysis,,${ }^{7,8}$ a measure based on a voxel-wise comparison of highly localized gray matter (GM) regions between two clinical groups. VBM tests for residual tissue concentration differences that remain after spatial normalization into the same standardized stereotaxic space and method calculations rate the within-voxel concentrations of GM (i.e., differences in the proportion of GM contained within a given voxel). ${ }^{9,10}$ Accordingly, the specific contribution of molecular imaging provided by nuclear medicine techniques such as Single Photon Emission Computed Tomography (SPECT) and Positron Emission Tomography (PET) has been profound, with major improvements regarding specificity, imaging resolution, and more recently, functional multimodality.

Early reports from structural studies have identified subcortical hyperintensities as macroscopic white matter (WM) changes which have been cited by several reports as associated with CVD-VCI, mood disor- ders, executive dysfunction and higher conversion to dementia. In functional terms, it is hypothesized that cognitive deficits observed in subcortical VCI arise when infarcts in the WM lead to the disruption of neuronal circuits connecting cortical and subcortical structures. Despite the substantial progress on the characterization of cognitive deficits and the early identification of minor vascular lesions, other important issues related to CVD, such as the neuropathological etiology of these lesions, remain a subject of intensive research in the last decade, with studies evolving to address the relationship between normal-appearing WM and amyloid angiopathy or Wallerian Degeneration. ${ }^{11-13}$ On the other hand, cerebral microbleeds (CMB) or cerebral microhemorrhages (CMH) are small hypointense lesions with variable cutoff size - typically between 5 and $10 \mathrm{~mm}$ - that have been attracting growing interest in recent years. Previous literature has shown an increased number of $\mathrm{CMBs}$ in MCI (around 11\%) and there is an extensive debate on the significance of these lesions in terms of higher conversion to dementia. ${ }^{14}$

In this brief review, we aim to summarize some of these novel implementations, both in the macro and microanatomy and radiotracer aspects, and discuss their impact on the diagnostic workup of age-related cognitive disorders, focusing on the field of VCI-VaD.

\section{METHODS}

A review of the literature (Table 1) published between January 2010 and 2017 was performed through searches on the electronic databases PubMed/MEDLINE (http://www.ncbi.nlm.nih.gov/pubmed/), Institute for Scientific Information Web of Knowledge (http://www. isiknowledge.com) and EMBASE (http://www.embase. com), using the following terms: "structural neuroimaging", "cerebrovascular", "vascular dementia", "vascular cognitive impairment" "aging", "diffusion tensor imaging", "DTI", "MRI”, "VBM", "molecular neuroimaging", "SPECT" and "PET" search. Firstly, the complete abstract was read, with the first paper selection. A second selection included the full reading of the papers. Articles were included if they focused on clinical and therapeutic applications of novel neuroimaging techniques in the assessment of cognitive symptoms of VCI-CVD-VaD. Although we designed a non-systematic review, article retrieval and selection were performed following the main recommendations of the Moose guidelines. ${ }^{15}$

\section{RESULTS}

A total of 790 articles were retrieved and 127 remained for further analysis, after primary exclusion. A total of 


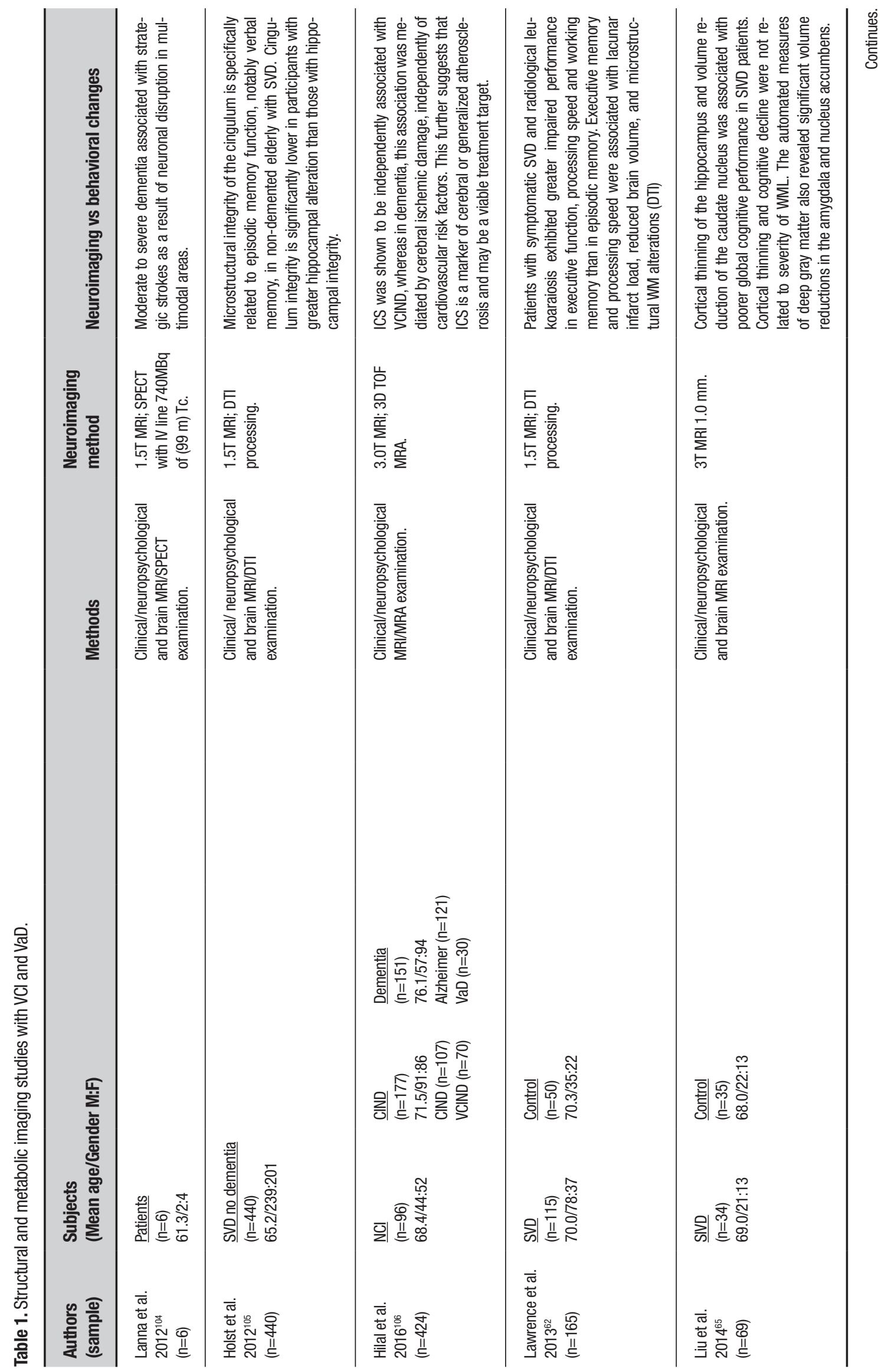




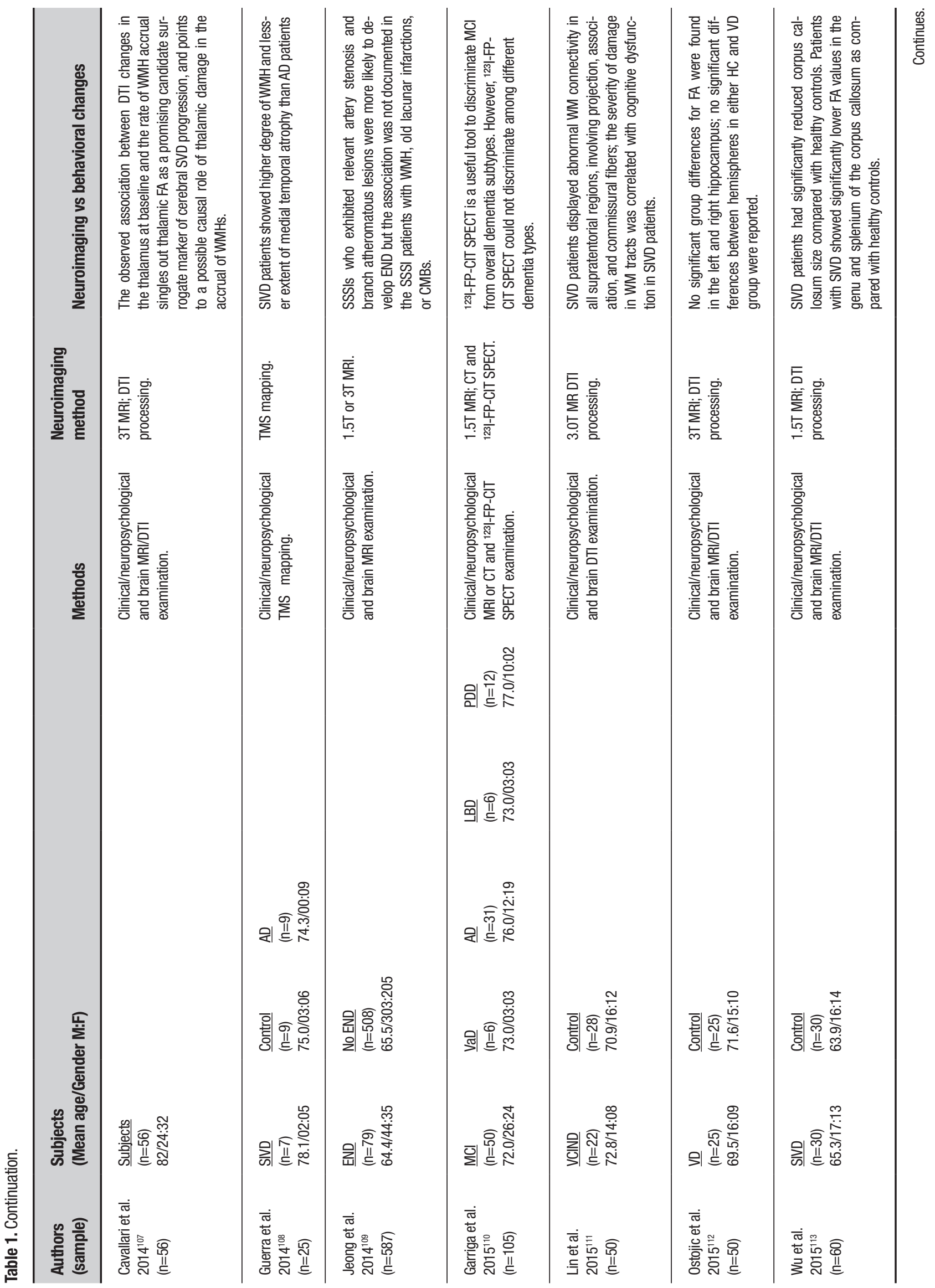




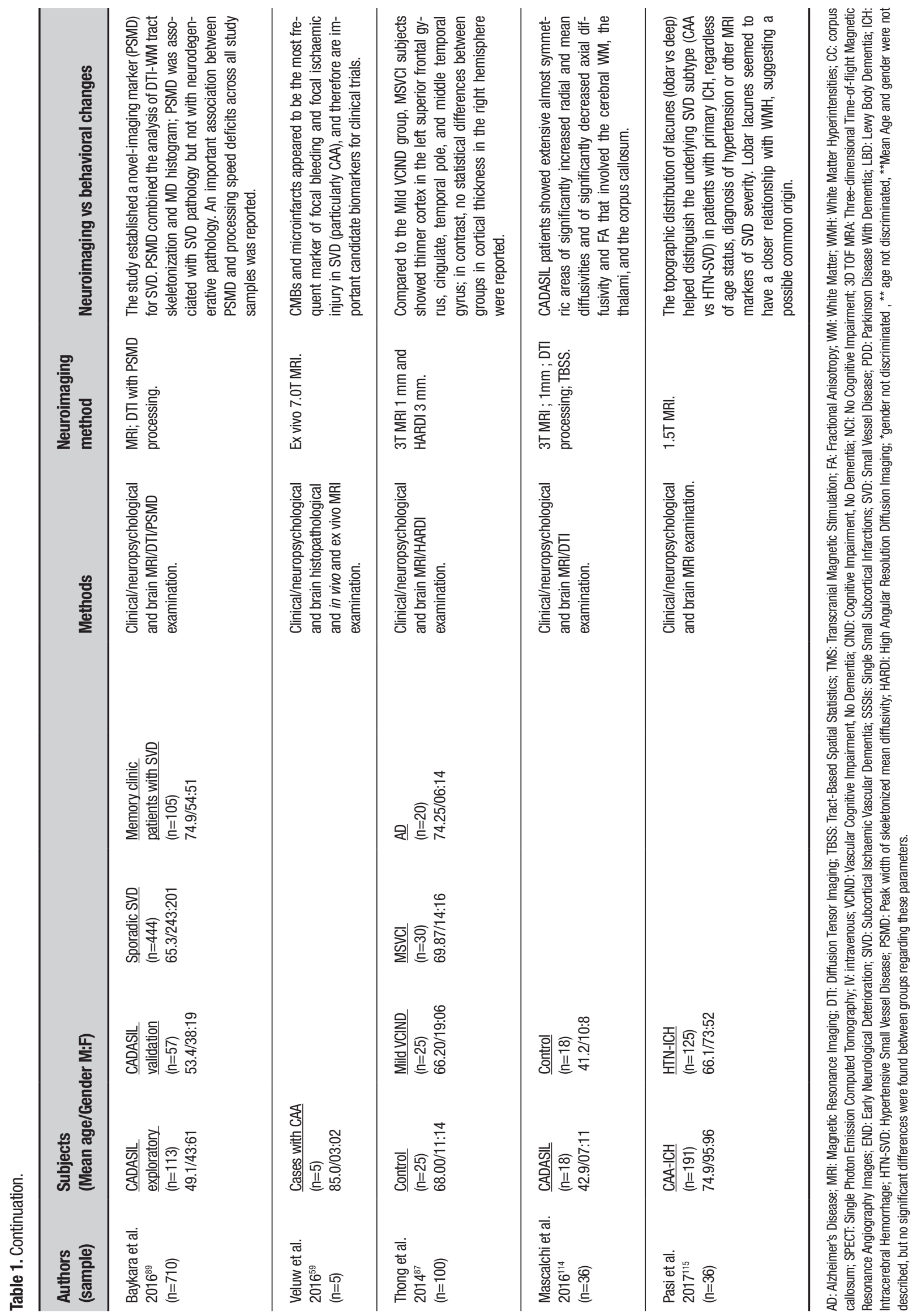


25 studies were subsequently considered eligible for inclusion and discussion.

PET and SPECT. Both PET and SPECT have been intensively applied in the last 20 years to quantify changes in regional brain function induced by age-related disorders $^{16,17}$ The most widely utilized PET tracer in cognitive disorders is 2-[18F] fluoro-2-Deoxy-D-glucose (FDG) PET for measurements of cerebral metabolic rate of glucose (CMRglc), an indicator of different parameters, e.g., neuronal activity, oxygen consumption, synaptic alterations and molecular changes. ${ }^{16,17}$ Studies have shown that CMRglc reductions occur in AD-risk states, ${ }^{14}$ in preclinical $A D,{ }^{18}$ and correlate with disease progression ${ }^{19}$ with higher accuracy than the Mini-Mental State Examination and ADAS-cog. ${ }^{20}$

Considerable technical improvements have been made in SPECT and PET methodology, propelling the introduction of modern hybrid technology, ${ }^{21}$ which has improved structural - functional assignments that have paved the way for SPECT/CT and PET/CT towards accepted clinical imaging standards. ${ }^{16,22}$ The beneficial effects of hybrid systems are clear for brain scans, since post-hoc software-based image fusion of independently acquired imaging data may be employed as a wellestablished and precise method. ${ }^{23}$ Advanced technology implemented in modern hybrid devices offers the opportunity to reduce image acquisition times, ${ }^{22}$ and to use low-dose $\mathrm{CT}$ for accurate attenuation correction of brain scans on SPECT/CT and PET/CT. More recently, with the advent of simultaneous MR/PET, ${ }^{24}$ novel solutions for adequate attenuation correction have been proposed, ${ }^{25-27}$ but also improved algorithms for head motion correction utilizing MRI-based motion tracking in combination with PET list mode data motion correction, ${ }^{28,29}$ having a major impact on the spatial resolution of brain imaging studies.

True multimodality. The most fundamental advantage of MR/PET is a major advancement in true multimodality, ${ }^{21,30}$ e.g. structural-functional and functionalfunctional. Due to the distinctiveness of structural MRI sequences yielding quantitative MR applications, ${ }^{31,32}$ a more refined clinical structural depiction of brain lesions has become possible, along with the functional characterization provided by PET tracer measurements.

Indeed, all the methodological improvements of recent years have also led to important enhancement in the diagnostic characterization of cognitive disorders, improving the specificity and sensitivity of human imaging biomarker studies. ${ }^{19}$ For instance, the possibility of full functional-functional multimodality in simultaneous MR/PET; hybrid protocols offer for instance parallel FDG PET and MRI-spectroscopic imaging ${ }^{24}$ improving the molecular imaging characterization of CVD and neurodegenerative disorders; or, parallel dynamic ligand acquisitions in combination with functional MRI techniques (e.g. BOLD fMRI, resting state fMRI, continuous arterial spin labeling, contrast-enhanced perfusion techniques, etc.) under pharmacological or non-pharmacological experimental challenges, are expected to advance molecular characterization of neurodegenerative disorders and CVD in clinical human neurosciences. Finally, improvements in PET imaging temporal resolution have opened a field for integrating time-of-flight ${ }^{33,34}$ information into the reconstruction process, leading to the high resolution of today's PET/CT systems, again, improving imaging capabilities, potentially reducing acquisition times and improving the specificity of the imaging set-up.

While in $\mathrm{AD}$ the best-recognized biomarkers that can be detected in cerebrospinal fluid and blood are amyloid- $\beta$, tau-protein and phosphorylated tau-protein (phospho-tau), for VaD no specific biomarker is available. Nevertheless, in VaD, FDG PET usually differentiates widespread areas of focal cortical and subcortical hypometabolism from the pattern typically found in $\mathrm{AD}$, with markedly lower metabolic rates in temporal-parietal lobes. ${ }^{17}$ Additionally, in VCI-VaD, the metabolic ratio seems to be generally higher than in the $\mathrm{AD}$ group. ${ }^{17}$ Another study conducted by Kim et al..$^{35}$ investigated the profile of negative [(subcortical vascular dementia) $(n=24)]$ and positive [(AD), $(n=81)]$ amyloid- $\beta$ patients using $11 \mathrm{C} \mathrm{PiB} \mathrm{PET}$. When compared to $\mathrm{AD}$, the negative amyloid- $\beta$ (subcortical vascular patients) cases showed more pronounced cortical thinning in the bilateral inferior frontal, superior temporal gyri and orbitofrontal lobes. Findings also evidenced that, in these areas, SVD independently contributed to cortical atrophy through different mechanisms than those of AD. ${ }^{35}$

More recently, F-18 labeled amyloid PET tracers have been introduced, including compounds such as [18F]Florbetaben, ${ }^{36-38}[18 \mathrm{~F}]$ Flutemetamol ${ }^{39,40}$ and [18F]Florbetapir. ${ }^{41,42}$ These novel compounds offer the major advantages of a longer half-life of the radioactive label (110 min), allowing a much wider distribution of amyloid PET scans, even in institutions without an on-line cyclotron facility. Another innovative method to specifically characterize $\mathrm{AD}$ pathology by $\mathrm{PET}$ imaging is through the use of selective in-vivo tau PET tracers, which allow the quantifying of tau aggregation in the brain. ${ }^{43,44}$ Neuropathological studies of $\mathrm{AD}$ show a strong association 
between tau deposits, decreased cognitive function, and neurodegenerative changes, and selective tau imaging enables these associations to be explored in vivo. ${ }^{43}$

Although qualitative findings achieved with amyloid tracers are robust, quantitative measures of amyloid tracer retention show considerable variability across centers. Therefore, standardization of acquisition protocols, subject management, tracer administration, image quality control, and image processing and analysis methods has become an important issue for improving the accuracy of quantitative amyloid PET measurements. ${ }^{45}$ This is of particular importance for longitudinal multi-center studies, and for improving the sensitivity of intervention effects targeting amyloid clearance. ${ }^{46}$ Recently, a novel method for standardization denominated 'Centiloids' was introduced, which attempts to standardize the quantitative amyloid data by relating "nonstandard" analysis methods to a 'standard' PIB PET data analysis and expressing the data after transformation into the so-called 'Centiloid scale'. ${ }^{45}$

\section{Quantitative Susceptibility Mapping (QSM) of the Brain.} Many biological processes, including regulation of protein expression, ${ }^{47,48}$ oxygen transport and neurotransmission require the presence of iron. The accumulation of iron may be found throughout normal aging, ${ }^{49,50}$ for instance in the basal ganglia and hippocampus and also in subcortical regions. ${ }^{49}$ In a variety of cognitive related disorders, including CVD, iron accumulation is thought to play an important role, possibly due to biochemical alterations related to neurodegeneration (e.g., oxidative stress, abnormal neuronal connectivity), although the exact mechanisms are not fully understood. In rodent models, iron deposition was associated with WM disruption and atrophy by inducing endothelial cell damage..$^{50,51}$ More recently, improved quality and accuracy in the quantification of iron by MRI has been achieved through quantitative susceptibility mapping (QSM). In the field of vascular-related disorders, despite limited data, there is increasing evidence pointing to iron accumulation in putamen and caudate nucleus when compared to healthy controls. $^{50,52}$ Similar findings were also reported with CADASIL (cerebral autosomal-dominant arteriopathy with subcortical infarcts and leukoencephalopathy), a genetically defined form of early SVD. ${ }^{52,53}$ Although most of the literature reported a predominant pattern of iron deposition in subcortical areas, accumulation in greater vessels has also been mentioned, in this case leading to more extensive vascular damage..$^{50}$ Taken together, these support the idea that iron accumula- tion is a marker of neurodegeneration and endothelial damage, regardless of the underlying process.

High field MRI of the Brain. The main advantage of $3.0 \mathrm{~T}$ over lower-field MR scanners is a better sign-to-noise ratio (SNR), which increases roughly linearly with the strength of the magnetic field..$^{54}$ From 2004 on, a number of studies have been conducted to assess white matter damage in diseases such as multiple sclerosis, ${ }^{32}$ Alzheimer's disease (AD), ${ }^{55}$ and adrenoleukodystrophy ${ }^{19}$ with 3.0 or $4.0 \mathrm{~T}$ MR scanners, and evaluation of iron deposition in neurodegenerative and cerebrovascular disease at $7 \mathrm{~T}^{49,54}$ Consequently, imaging at 3.0 $\mathrm{T}$ enables higher-resolution scanning with larger imaging matrices, thinner slices and more detail on anatomical structure, without extending (or extending minimally) the scan acquisition time. These advantages come with a trade-off of increased sensitivity to field inhomogeneity (deviation of the local magnetic field from its average value) and changes in relaxation times, in turn producing changes in image contrast. ${ }^{54}$ At comparable acquisition times, images obtained at 3.0 T have a higher quality with an improved resolution over images obtained at $1.5 \mathrm{~T}$. Alternatively, 3.0 T MRI can be used to obtain acceptable images, similar to those obtained at $1.5 \mathrm{~T}$, but at a fraction of the time, thus reducing potential motion artifacts and providing greater comfort for patients.

Regarding the study of vascular-related pathology, a major development is underway, particularly with the advent of $7 \mathrm{~T}$ MRI; previous attempts have been made to distinguish between vascular occlusion and microinfarction versus demyelinating disease, for instance in the differential diagnosis at $7 \mathrm{~T}$ between Susac syndrome and Multiple Sclerosis. ${ }^{56,57}$ Accordingly, the anatomic modifications involving dilated perivascular spaces have been investigated and quantified with greater accuracy using $7 \mathrm{~T}$ MRI ${ }^{58}$ showing different patterns and quantification, for instance, in stroke, migraine, CADASIL, dementia, $\mathrm{AD}$, and mild cognitive impairment. Furthermore, $7 \mathrm{~T}$ studies may be more successful in providing a more detailed picture of the neuropathology of closely related conditions, such as the case of cerebral microinfarcts, whose regional distribution (intracortical and juxtacortical location ${ }^{59}$ may indicate chronic or acute lesions, with the latter being described as gliotic cerebral microinfarcts with hemorrhagic components. These findings can be confidently extended by in vivo MRI in the context of aging and dementia.

Another useful tool for analyzing subcortical vascular lesions is to mask white matter hyperintensities 
(WHM). Some of the methods are based on the Expectation-Maximization (EM) algorithm, ${ }^{60}$ which differentiates brain tissue into WM, GM and cerebrospinal fluid (CSF). In addition, tissue segmentation from T1 and Flair images through the EM algorithm also enables the segmentation of lacunar infarcts ${ }^{61}$ Finally, the combination of high-field MRI techniques and novel image sequences, particularly susceptibility-weighted imaging (SWI), has improved the detection of CMB. ${ }^{14}$

Cortical thinning and cortical surface analysis. Hippocampal and GM reductions are often described in different forms of CVD and may indicate, with greater likelihood, conversion to dementia. ${ }^{7}$ In subjects with subcortical ischaemic vascular dementia (SIVD), several studies have observed decreased gray matter both in the total volume ${ }^{62}$ or in regional territories, ${ }^{7,63}$ for instance the frontal and temporal lobes. In addition, hippocampal volume atrophy, particularly in the CA1 subfield, seems to be vulnerable to vascularrelated events, for instance, hypoxia and ischemia, as suggested by rodent-model ${ }^{64}$ and structural neuroimaging $^{65}$ investigations. More recently, it has been shown that cortical volume, surface area and cortical thickness are closely related, and a reduction in cortical volume may affect either thickness or surface area (or both). ${ }^{65}$ Initial studies have attempted to investigate cortical thinning and found reduction in the perisylvian, medial frontal area and posterior cingulate. ${ }^{35,66}$ More recently, surface area in gray matter has been found to be reduced in SIVD, particularly in the left temporal lobe and dorsolateral PFC. ${ }^{65}$ Possibly, cortical thinning and atrophy play a greater role in cognitive decline than the occurrence of WML. ${ }^{67}$ Taken together, these findings provide further support for the close relationship between vascular and neurodegeneration, highlighting the anatomical relevance of the perisylvian area as a highly sensitive territory to the effects of cortical thinning, possibly due to ischemic damage of lateral cholinergic pathways and disruption of fibers connecting the nucleus basalis of Meynert to frontoparietal and temporal areas. ${ }^{68}$

The use of support vector machines in CVD. The last decade has witnessed a great deal of effort in the development of methods to quantitatively assess specific CVD markers and devise metrics allowing the quantification of total CVD burden..$^{69}$ Regarding data analysis, machine learning-based algorithms for dementia classification according to the expression of AD-typical metabolic patterns (but also other imaging parameters) are recent developments and have been influencing the field of cerebrovascular disorders. The most employed algorithms include K-means clustering, artificial neural network, random forest and support vector machine (SVM); the potential advantage of SVM is the classification of more than one biomarker combined, further improving performance accuracy, as demonstrated by studies matching FDG-PET and structural MRI, which yielded higher accuracy rates compared to single modality classification. ${ }^{70,71}$

Despite the enthusiasm and great potential of these methods, problems in defining threshold and clustering approach and the statistical inference for SVM and the use of permutation tests that ignore SVM margin still limit the wide applicability of these methods. Furthermore, a number of drawbacks remain regarding the limited evaluation of findings, particularly the clinical interpretation of disease mechanisms according to the classifier's decision. ${ }^{69}$ Possibly in the future, a better quantification of the total brain burden of CVD through machine learning-based algorithms will help promote both the stratification of patients (rather than using individual features) and understanding of the causeeffect relationship between events that ultimately leads to CVD. Hence, the ambitious achievements of advanced methods of CVD open a large avenue to unravel the core neuropathological mechanisms (e.g., axonal degeneration, myelin breakdown) related to vascular disease. ${ }^{6}$ In the clinical scenario, there is great hope that, in the years to come, SVM can be employed to identify and reverse vascular tissue disease at earlier stages, before lesions become apparent. ${ }^{69}$

Diffusion tensor imaging (DTI) and tractography. Diffusion tensor imaging (DTI) is a variant of MRI that noninvasively measures the diffusion of water in vivo brain tissues, ${ }^{72-74}$ that is highly sensitive for evaluating the microstructure of WM, including the study of axonal organization, density of the fibers and even the integrity of the myelin sheath. ${ }^{72,75}$ One of the most common proxies of DTI is fractional anisotropy or anisotropy fraction (FA), an indirect measure of the molecule direction in a given set of fibers and bundles of a brain structure. ${ }^{72,73,76}$ An increasing body of evidence has demonstrated an association of WM microstructural abnormalities and FA decreases in the deep WM and corpus callosum of patients with VCI compared to healthy controls. ${ }^{9}$ Although largely unknown and somewhat speculative, a number of studies have also linked low FA measurements to reduced WM density, loss of axonal coherence of axonal fibers (loss of struc- 


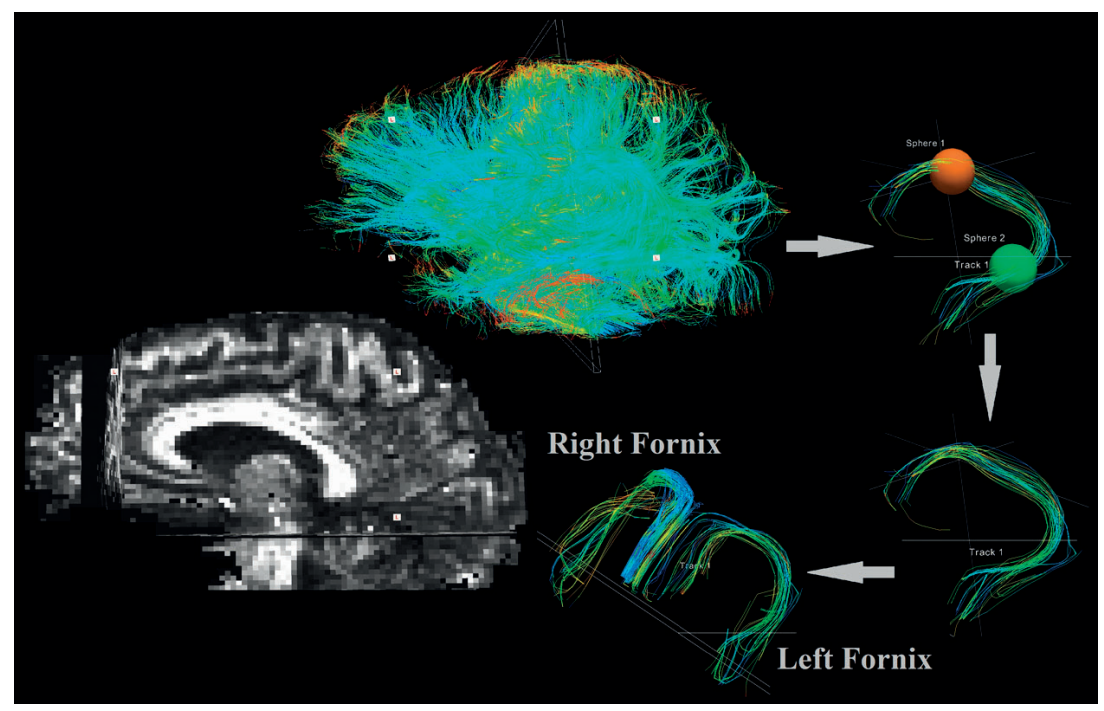

Figure 1. Depiction of virtual delineation by deterministic tractography (Trackvis protocol for tract delineation). Fornix fibers (left and right) are visualized as blue fibers. Figure originally designed by the authors of the manuscript. tural organization), and changes in membrane water permeability. ${ }^{77}$ Another promising approach of DTI in a variety of neuropsychiatric disorders ${ }^{78-83}$ is the use of tractography, which allows non-invasive three-dimensional identification of fiber tracts ${ }^{74,84}$ and enables WM bundle reconstruction typically found in post mortem analysis. ${ }^{85}$ Tractography is based on fiber connectivity probability and anisotropic water movement in a specific group of fibers and their surroundings. The technique can be either global or local, probabilistic or deterministic ${ }^{86}$ (Figure 1).

The use of the isotropic HARDI technique, including single shot sequences with no interslice gaps and use of the HARDI atlas, seems to provide more powerful computational analysis and higher precision anatomical examination of WM integrity. ${ }^{87,88}$ For instance, moderate to severe VCI exhibited increased mean diffusivity (MD) in the temporal lobe and decreased FA in the corpus callosum, superior longitudinal fasciculus (SLF), internal capsule (IC), corona radiate (CR), thalamus and uncinate fasciculus (UNC). ${ }^{87}$ Interestingly, no differences in $\mathrm{MD}$ or FA were found between $\mathrm{AD}$ and $\mathrm{VCI}$ and this may point to distinct trajectories of fiber bundles compromised by these two conditions. In the neuroprogression of $\mathrm{AD}$, for instance, while the posterior U-fibers of the superior longitudinal fasciculus are often compromised, in VCI the most common pattern includes the involvement of neocortical anterior bundles, typically long association fibers, such as the UNC and IC/CR. ${ }^{87}$

Another interesting technique is the peak width of skeletonized mean diffusivity (PSMD), which is based on the analysis of fiber tracts and on the difference between the 95th and the 5th percentiles of the voxel-based MD values within the WM skeleton. ${ }^{89}$ Increasing evidence has shown that the PSMD may substantially reduce contamination from CSF and other spurious structures and enhance the sensitivity of SVD total burden measures. ${ }^{69}$ Recent evidence also indicates greater sensitivity of the PSMD for rating the progression of injury from SVD than the individual volumetric measures of $\mathrm{WMH}$, lacunes and brain total volume. In a cross-sectional investigation of 69 patients with CADASIL, processing speed emerged as the most prominent cognitive domain affected..$^{89}$ The use of STRIVE ${ }^{89,90}$ criteria on T2-weighted gradient echo images has been employed for the identification of CMB. Conversely, lacunar volumes could be rated by placing a seed-growing algorithm where a seed voxel is placed into a lacune on the 3D-T1 image. ${ }^{89}$

Magnetization transfer (MT). Magnetization transfer (MT) imaging, or magnetization transfer contrast (MTC) magnetic resonance imaging, is a modality of MRI technique based upon the exchange between bonded water in the brain tissue and proton magnetization in free water to characterize brain tissue properties quantitatively. ${ }^{91,92}$ The magnetization transfer ratio (MTR), derived from MT imaging, has been explored and used to evaluate brain injury in different brain diseases, e.g., multiple sclerosis, Alzheimer's disease, stroke, and epilepsy. In the field of vascular disease, although early reports have been available since 1999, only a small number of studies have employed this approach. One of these investigations included 56 subjects with WML and showed that periventricular WM had lower MTR than deep WM. ${ }^{93}$ Such findings were replicated by later studies showing an association of cognitive impairment with either larger periventricular $\mathrm{WM}^{94-96}$ or reduced 
MTR in normal appearing white matter (NAWM). ${ }^{97}$ Overall, these studies also support previous evidence showing reduced periventricular MTR in subjects with Binswanger disease (whose cognitive impairment is associated with a proportion of subcortical WML over 25\%) compared to non-demented subjects with similar severity of WML, and seem to confirm the sensitivity of MTR for detecting clinically relevant CVD.

\section{CONCLUSIONS}

This review briefly summarizes some of the most promising neuroimaging techniques addressing brain structural and metabolic changes in CVD. Indeed, much has been achieved in terms of unraveling the neuropathological underpinnings and clinical correlates of VCI and $\mathrm{VaD}$; a number of controversial issues, however, still remain. While on the one hand, neuroimaging has evolved quickly in the development of powerful and sensitive methods for studying in vivo brain architecture in CVD and related cognitive disorders, most structural techniques are limited by a number of pitfalls. The source of criticism centers on multiple aspects, including the large variability in imaging modalities and procedures (e.g., threshold values for cluster definition), the limited accuracy of DTI-MRI (poor identification of crossing fibers, poor specificity of findings) and low replication of results. 98,99

Despite the aforementioned limitations, novel neuroimaging methods offer an enthusiastic debate on the interplay between aging, neurodegeneration and vascular disease; one interesting topic involves, for instance, the pattern of cortical thinning exhibited by CVD and other related cognitive disorders. Indeed, a pattern of cortical thinning in frontal and subcortical areas seem to be closely related to SIVD, contrasting with the temporoparietal and medial temporal findings typically observed in $\mathrm{AD} .{ }^{35,100}$ Another point of controversy is based on the nature of cortical changes observed in CVD. While much has been discussed on the complex interaction between neurodegeneration and vascular disease, current evidence also suggests that CVD may independently lead to cortical atrophy. ${ }^{35} \mathrm{WMH}$ may possibly cause subcortical axonal damage and neuronal disruption of cortical pathways, leading to secondary neuronal body damage and ultimately gray matter atrophy. ${ }^{35,101}$ Contrasting with the hypothesis of vascular-induced cortical atrophy is the Wallerian degeneration model, which basically conceives WM atrophy as a product of gray matter progressive reduction. ${ }^{11,99,102,103}$

Thus, the continuous development of brain imaging techniques through new metabolic tracers, molecular compounds, multimodal approaches, microstructural anatomy, disease classifying algorithms and higher field MRI offer an exciting perspective towards a broad comprehension of CVD pathophysiology. Although the importance of most of these techniques in the clinical setting has yet to be recognized, there is great expectancy in achieving earlier and more refined therapeutic interventions for the effective management of dementia.

Author contributions. All authors have contributed significantly to the study and are in agreement with the content of the manuscript.

\section{REFERENCES}

1. Inzitari D, Pracucci G, Poggesi A, Carlucci G, Barkhof F, Chabriat H, et al. Changes in white matter as determinant of global functional decline in older independent outpatients: three year follow-up of LADIS (leukoaraiosis and disability) study cohort. BMJ. 2009;339:b2477.

2. Frisoni GB, Galluzzi S, Pantoni L, Filippi M. The effect of white matter lesions on cognition in the elderly--small but detectable. Nat Clin Pract Neurol. 2007;3(11):620-7.

3. Jokinen H, Ryberg C, Kalska H, Ylikoski R, Rostrup E, Stegmann MB, et al. Corpus callosum atrophy is associated with mental slowing and executive deficits in subjects with age-related white matter hyperintensities: the LADIS Study. J Neurol Neurosurg Psychiatry. 2007;78(5):491-6.

4. Frisoni GB, Galluzzi S, Pantoni L, Filippi M. The effect of white matter lesions on cognition in the elderly--small but detectable. Nat Clin Pract Neurol. 2007;3(11):620-7.

5. Sudo FK, Alves CEO, Alves GS, Ericeira-Valente L, Tiel C, Moreira DM, et al. White matter hyperintensities, executive function and global cognitive performance in vascular mild cognitive impairment. Arq Neuropsiquiatr. 2013;71(7):431-6.

6. Perneczky R, Tene O, Attems J, Giannakopoulos P, Ikram MA, Federico $A$, et al. Is the time ripe for new diagnostic criteria of cognitive impairment due to cerebrovascular disease? Consensus report of the International Congress on Vascular Dementia working group. BMC Med. 2016. DOI 10.1186/s12916-016-0719-y

7. Li C, Du H, Zheng J, Wang J. A Voxel-based Morphometric Analysis of Cerebral Gray Matter in Subcortical Ischemic Vascular Dementia Patients and Normal Aged Controls. Int J Med Sci. 2011;8(6):482-6.

8. Mechelli A, Price C, Friston K, Ashburner J. Voxel-Based Morphometry of the Human Brain: Methods and Applications. Curr Med Imaging Rev. 2005;1(2):105-13.

9. Ashburner J, Friston KJ. Voxel-based morphometry--the methods. Neurolmage. 2000;11(6 Pt 1):805-21.

10. Ashburner J, Friston KJ. Why voxel-based morphometry should be used. Neurolmage. 2001;14(6):1238-43.

11. Stricker NH, Schweinsburg BC, Delano-Wood L, Wierenga CE, Bangen $\mathrm{KJ}$, Haaland KY, et al. Decreased white matter integrity in late-myelinating fiber pathways in Alzheimer's disease supports retrogenesis. NeuroImage. 2009;45(1):10-6.

12. Thomalla G, Glauche V, Weiller C, Röther J. Time course of wallerian degeneration after ischaemic stroke revealed by diffusion tensor imaging. J Neurol Neurosurg Psychiatry. 2005;76(2):266-8.

13. Di Paola M, Di lulio F, Cherubini A, Blundo C, Casini AR, Sancesario G, et al. When, where, and how the corpus callosum changes in $\mathrm{MCl}$ and AD: a multimodal MRI study. Neurology. 2010;74(14):1136-42.

14. Haller S, Garibotto V, Kövari E, Bouras C, Xekardaki A, Rodriguez C, et al. Neuroimaging of dementia in 2013: what radiologists need to know. Eur Radiol. 2013;23(12):3393-404. 
15. Stroup DF. Meta-analysis of Observational Studies in EpidemiologyA Proposal for Reporting. JAMA. 2000;283(15):2008.

16. Bybel B, Brunken RC, Shah SN, Wu G, Turbiner E, Neumann DR. PET and PET/CT imaging: what clinicians need to know. Cleve Clin J Med. 2006;73(12):1075-87.

17. Heiss W-D, Zimmermann-Meinzingen S. PET imaging in the differentia diagnosis of vascular dementia. J Neurol Sci. 2012;322(1-2):268-73.

18. Albert MS, DeKosky ST, Dickson D, Dubois B, Feldman HH, Fox NC, et al. The diagnosis of mild cognitive impairment due to Alzheimer's disease: recommendations from the National Institute on Aging-Alzheimer's Association workgroups on diagnostic guidelines for Alzheimer's disease. Alzheimers Dement J Alzheimers Assoc. 2011;7(3):270-9.

19. Herholz K, Boecker H, Nemeth I, Dunn G. FDG PET in dementia multicenter studies and clinical trials. Clin Transl Imaging. 2013;1(4):261-70.

20. Landau SM, Harvey D, Madison CM, Koeppe RA, Reiman EM, Foster $\mathrm{NL}$, et al. Associations between cognitive, functional, and FDG-PET measures of decline in AD and MCl. Neurobiol Aging. 2011;32(7): 1207-18.

21. Townsend DW. Multimodality imaging of structure and function. Phys Med Biol. 2008:53(4):R1-39.

22. Mariani G, Bruselli L, Kuwert T, Kim EE, Flotats A, Israel O, et al. A review on the clinical uses of SPECT/CT. Eur J Nucl Med Mol Imaging. 2010;37(10):1959-85

23. Barra V, Boire JV. A general framework for the fusion of anatomical and functional medical images. Neurolmage. 2001;13(3):410-24.

24. Schlemmer H-PW, Pichler BJ, Schmand M, Burbar Z, Michel C, Ladebeck $R$, et al. Simultaneous MR/PET imaging of the human brain: feasibility study 1 . Radiology. 2008;248(3):1028-35.

25. Yang X, Fei B. Multiscale segmentation of the skull in MR images for MRIbased attenuation correction of combined MR/PET. J Am Med Inform Assoc JAMIA. 2013;20(6):1037-45.

26. Bini J, Izquierdo-Garcia D, Mateo J, Machac J, Narula J, Fuster V, et al. Preclinical evaluation of MR attenuation correction versus $\mathrm{CT}$ attenuation correction on a sequential whole-body MR/PET scanner. Invest Radiol. 2013;48(5):313-22.

27. Catana C, van der Kouwe A, Benner T, Michel CJ, Hamm M, Fenchel $\mathrm{M}$, et al. Toward implementing an MRI-based PET attenuation-correction method for neurologic studies on the MR-PET brain prototype. J Nuc Med Off Publ Soc Nucl Med. 2010;51(9):1431-8.

28. Ullisch MG, Scheins JJ, Weirich C, Rota Kops E, Celik A, Tellmann L, et al. MR-based PET motion correction procedure for simultaneous MR-PET neuroimaging of human brain. PloS One. 2012;7(11):e48149.

29. Catana C, Benner T, van der Kouwe A, Byars L, Hamm M, Chonde DB, et al. MRI-assisted PET motion correction for neurologic studies in an integrated MR-PET scanner. J Nucl Med Off Publ Soc Nucl Med. 2011; 52(1):154-61.

30. Cherry SR. Multimodality Imaging: Beyond PET/CT and SPECT/CT. Semin Nucl Med. 2009;39(5):348-53

31. Bauer $S$, Wagner M, Seiler A, Hattingen E, Deichmann R, Nöth U, et al. Quantitative T2'-mapping in acute ischemic stroke. Stroke J Cereb Circ. 2014;45(11):3280-6.

32. Jurcoane A, Wagner M, Schmidt C, Mayer C, Gracien R-M, Hirschmann $\mathrm{M}$, et al. Within-lesion differences in quantitative MRI parameters predict contrast enhancement in multiple sclerosis. J Magn Reson Imaging. 2013;38(6):1454-61

33. Nagaki A, Onoguchi M, Matsutomo N. Clinical validation of high-resolution image reconstruction algorithms in brain 18F-FDG-PET: effect of incorporating Gaussian filter, point spread function, and time-of-flight. Nucl Med Commun. 2014;35(12):1224-32.

34. Leemans EL, Kotasidis F, Wissmeyer M, Garibotto V, Zaidi H. Qualitative and quantitative evaluation of blob-based time-of-flight PET image reconstruction in hybrid brain PET/MR imaging. Mol Imaging Biol. 2015;1-10.

35. Hun KC, Won SS, Ha KG, Soo SJ, Hanna C, Young N, et al. Cortical Thinning in Subcortical Vascular Dementia with Negative. J Alzheimer Dis. 2012;(2):315-23.

36. Barthel H, Sabri O. Florbetaben to trace amyloid- $\beta$ in the Alzheimer brain by means of PET. J Alzheimers Dis JAD. 2011;26 Suppl 3:117-21.

37. Barthel H, Gertz H-J, Dresel S, Peters O, Bartenstein P, Buerger K, et al. Cerebral amyloid- $\beta$ PET with florbetaben (18F) in patients with Alzheimer's disease and healthy controls: a multicentre phase 2 diagnostic study. Lancet Neurol. 2011:10(5):424-35.

38. Becker GA, Ichise M, Barthel H, Luthardt J, Patt M, Seese A, et al. PET quantification of $18 \mathrm{~F}$-florbetaben binding to $\beta$-amyloid deposits in human brains. J Nucl Med Off Publ Soc Nucl Med. 2013;54(5):723-31.
39. de Lartigue J. Flutemetamol (18F): a $\beta$-amyloid positron emission tomography tracer for Alzheimer's and dementia diagnosis. Drugs Today Barc Spain 1998. 2014;50(3):219-29.

40. Thal DR, Beach TG, Zanette M, Heurling K, Chakrabarty A, Ismail A, et al. [(18)Ffflutemetamol amyloid positron emission tomography in preclinical and symptomatic Alzheimer's disease: specific detection of advanced phases of amyloid- $\beta$ pathology. Alzheimers Dement J Alzheimers Assoc. 2015; $11(8): 975-85$

41. Joshi AD, Pontecorvo MJ, Clark CM, Carpenter AP, Jennings DL, Sadowsky $\mathrm{CH}$, et al. Performance characteristics of amyloid PET with florbetapir F 18 in patients with alzheimer's disease and cognitively normal subjects. J Nucl Med Off Publ Soc Nucl Med. 2012;53(3):378-84

42. Kobylecki C, Langheinrich T, Hinz R, Vardy ERLC, Brown G, Martino $\mathrm{M}-\mathrm{E}$, et al. 18F-florbetapir PET in patients with frontotemporal dementia and Alzheimer disease. J Nucl Med Off Publ Soc Nucl Med. 2015 56(3):386-91

43. Hall B, Mak E, Cervenka S, Aigbirhio FI, Rowe JB, O'Brien JT. In vivo tau PET imaging in dementia: Pathophysiology, radiotracer quantification, and a systematic review of clinical findings. Ageing Res Rev. 2017;36:50-63

44. Fodero-Tavoletti MT, Okamura N, Furumoto S, Mulligan RS, Connor AR, McLean CA, et al. 18F-THK523: a novel in vivo tau imaging ligand for Alzheimer's disease. Brain J Neurol. 2011;134(Pt 4):1089-100.

45. Klunk WE, Koeppe RA, Price JC, Benzinger TL, Devous MD, Jagust WJ, et al. The Centiloid Project: standardizing quantitative amyloid plaque estimation by PET. Alzheimers Dement J Alzheimers Assoc. 2015:11(1):1-15.e1-4.

46. Asih PR, Chatterjee P, Verdile G, Gupta VB, Trengove RD, Martins RN Clearing the amyloid in Alzheimer's: progress towards earlier diagnosis and effective treatments - an update for clinicians. Neurodegener Dis Manag. 2014;4(5):363-78.

47. Friedlich AL, Tanzi RE, Rogers JT. The 5'-untranslated region of Parkinson's disease alpha-synuclein messengerRNA contains a predicted iron responsive element. Mol Psychiatry. 2007;12(3):222-3.

48. Rogers JT, Randall JD, Cahill CM, Eder PS, Huang X, Gunshin H, et al. An iron-responsive element type II in the 5'-untranslated region of the Alzheimer's amyloid precursor protein transcript. J Biol Chem. 2002 277(47):45518-28

49. De Reuck JL, Deramecourt V, Auger F, Durieux N, Cordonnier C, Devos $D$, et al. Iron deposits in post-mortem brains of patients with neurodegenerative and cerebrovascular diseases: a semi-quantitative 7.0 T magnetic resonance imaging study. Eur J Neurol. 2014:21(7):1026-31.

50. Moon Y, Han S-H, Moon W-J. Patterns of Brain Iron Accumulation in Vascular Dementia and Alzheimer's Dementia Using Quantitative Susceptibility Mapping Imaging. J Alzheimers Dis. 2016;51(3):737-45.

51. Won SM, Lee JH, Park UJ, Gwag J, Gwag BJ, Lee YB. Iron mediates endothelial cell damage and blood-brain barrier opening in the hippocampus after transient forebrain ischemia in rats. Exp Mol Med. 2011:43(2):121-8.

52. Liem MK, Lesnik Oberstein SAJ, Versluis MJ, Maat-Schieman MLC, Haan $\mathrm{J}$, Webb AG, et al. 7 T MRI reveals diffuse iron deposition in putamen and caudate nucleus in CADASIL. J Neurol Neurosurg Psychiatry. 2012;83(12):1180-5

53. Liu C, Li C, Yang J, Gui L, Zhao L, Evans AC, et al. Characterizing brain iron deposition in subcortical ischemic vascular dementia using susceptibility-weighted imaging: An in vivo MR study. Behav Brain Res. 2015;288:33-8

54. Rocca MA, Gerevini S, Filippi M, Falini A. High-Field-Strength MRI (3.0 T or More) in White Matter Diseases. In: Scarabino T, Pollice S, Popolizio T, editors. High Field Brain MRI [Internet]. Cham: Springer International Publishing; 2017 [cited 2017 Jul 3]. p. 223-37.

55. O'Dwyer L, Lamberton F, Bokde ALW, Ewers M, Faluyi YO, Tanner C, et al. Multiple Indices of Diffusion Identifies White Matter Damage in Mild Cognitive Impairment and Alzheimer's Disease. PLoS One. 2011;6(6): e21745.

56. García-Carrasco M, Mendoza-Pinto C, Cervera R. Diagnosis and classification of Susac syndrome. Autoimmun Rev. 2014;13(4-5):347-50.

57. Wuerfel J, Sinnecker T, Ringelstein EB, Jarius S, Schwindt W, Niendorf T, et al. Lesion morphology at 7 Tesla MRI differentiates Susac syndrome from multiple sclerosis. Mult Scler J. 2012;18(11):1592-9.

58. Cai K, Tain R, Das S, Damen FC, Sui Y, Valyi-Nagy T, et al. The feasibility of quantitative MRI of perivascular spaces at 7T. J Neurosci Methods. 2015;256:151-6.

59. van Veluw SJ, Zwanenburg JJ, Rozemuller AJ, Luijten PR, Spliet WG, 
Biessels GJ. The Spectrum of MR Detectable Cortical Microinfarcts: A Classification Study with 7-Tesla Postmortem MRI and Histopathology. J Cereb Blood Flow Metab. 2015;35(4):676-83.

60. Van Leemput K, Maes F, Vandermeulen D, Suetens P. Automated modelbased tissue classification of MR images of the brain. IEEE Trans Med Imaging. 1999;18(10):897-908.

61. Koikkalainen J, Rhodius-Meester H, Tolonen A, Barkhof F, Tijms B, Lemstra AW, et al. Differential diagnosis of neurodegenerative diseases using structural MRI data. Neurolmage Clin. 2016;11:435-49.

62. Lawrence AJ, Patel B, Morris RG, MacKinnon AD, Rich PM, Barrick TR, et al. Mechanisms of Cognitive Impairment in Cerebral Small Vessel Disease: Multimodal MRI Results from the St George's Cognition and Neuroimaging in Stroke (SCANS) Study. PLoS One. 2013;8(4):e61014.

63. Du AT, Schuff N, Laakso MP, Zhu XP, Jagust WJ, Yaffe K, et al. Effects of subcortical ischemic vascular dementia and $A D$ on entorhinal cortex and hippocampus. Neurology. 2002;58(11):1635-41.

64. Kitamura A, Fujita Y, Oishi N, Kalaria RN, Washida K, Maki T, et al. Selective white matter abnormalities in a novel rat model of vascular dementia. Neurobiol Aging. 2012;33(5):1012.e25-35.

65. Liu C, Li C, Gui L, Zhao L, Evans AC, Xie B, et al. The pattern of brain gray matter impairments in patients with subcortical vascular dementia. J Neurol Sci. 2014;341(1-2):110-8.

66. Seo SW, Lee J-M, Im K, Park J-S, Kim S-H, Kim ST, et al. Cardiovascular Risk Factors Cause Cortical Thinning in Cognitively Impaired Patients: Relationships Among Cardiovascular Risk Factors, White Matter Hyperintensities, and Cortical Atrophy. Alzheimer Dis Assoc Disord. 2012;26(2):106-12.

67. Viswanathan A, Godin O, Jouvent E, O'Sullivan M, Gschwendtner A, Peters N, et al. Impact of MRI markers in subcortical vascular dementia: A multi-modal analysis in CADASIL. Neurobiol Aging. 2010; 31(9): 1629-36.

68. Selden N. Trajectories of cholinergic pathways within the cerebral hemispheres of the human brain. Brain. 1998;121(12):2249-57.

69. Blair GW, Hernandez MV, Thrippleton MJ, Doubal FN, Wardlaw JM. Advanced Neuroimaging of Cerebral Small Vessel Disease. Curr Treat Options Cardiovasc Med. 2017;19(7):56

70. Dukart J, Mueller K, Barthel H, Villringer A, Sabri O, Schroeter ML, et al. Meta-analysis based SVM classification enables accurate detection of Alzheimer's disease across different clinical centers using FDG-PET and MRI. Psychiatry Res Neuroimaging. 2013;212(3):230-6.

71. Dukart J, Mueller K, Horstmann A, Barthel H, Möller HE, Villringer A, et al. Combined evaluation of FDG-PET and MRI improves detection and differentiation of dementia. PLoS One. 2011;6(3):e18111.

72. Beaulieu C. The basis of anisotropic water diffusion in the nervous system - a technical review. NMR Biomed. 2002;15(7-8):435-55.

73. Assaf $Y$, Pasternak O. Diffusion tensor imaging (DTI)-based white matter mapping in brain research: a review. J Mol Neurosci MN. 2008;34(1):51-61

74. Nucifora PGP, Verma R, Lee S-K, Melhem ER. Diffusion-Tensor MR Imaging and Tractography: Exploring Brain Microstructure and Connectivity1. Radiology. 2007;245(2):367-84

75. Emsell L, Leemans A, Langan C, Van Hecke W, Barker GJ, McCarthy $\mathrm{P}$, et al. Limbic and Callosal White Matter Changes in Euthymic Bipolar I Disorder: An Advanced Diffusion Magnetic Resonance Imaging Tractography Study. Biol Psychiatry. 2013;73(2):194-201.

76. Beaulieu C, Does MD, Snyder RE, Allen PS. Changes in water diffusion due to Wallerian degeneration in peripheral nerve. Magn Reson Med. 1996;36(4):627-31.

77. Ciccarelli O, Catani M, Johansen-Berg H, Clark C, Thompson A. Diffusion-based tractography in neurological disorders: concepts, applications, and future developments. Lancet Neurol. 2008;7(8):715-27.

78. Behrens TEJ, Johansen-Berg H, Woolrich MW, Smith SM, WheelerKingshott $\mathrm{C}$ a. M, Boulby PA, et al. Non-invasive mapping of connections between human thalamus and cortex using diffusion imaging. Nat Neurosci. 2003;6(7):750-7.

79. Psomiades M, Fonteneau C, Mondino M, Luck D, Haesebaert F, SuaudChagny $\mathrm{M}-\mathrm{F}$, et al. Integrity of the arcuate fasciculus in patients with schizophrenia with auditory verbal hallucinations: A DTI-tractography study. Neurolmage Clin. 2016;12:970-5.

80. Fitzsimmons J, Hamoda HM, Swisher T, Terry D, Rosenberger G, Seidman LJ, et al. Diffusion tensor imaging study of the fornix in first episode schizophrenia and in healthy controls. Schizophr Res. 2014; 156(2-3):157-60
81. Ji A, Godwin D, Rutlin J, Kandala S, Shimony JS, Mamah D. Tract-based analysis of white matter integrity in psychotic and nonpsychotic bipolar disorder. J Affect Disord. 2017;209:124-34.

82. Haarman BCM, Riemersma-Van der Lek RF, Burger $H$, de Groot JC, Drexhage HA, Nolen WA, et al. Diffusion tensor imaging in euthymic bipolar disorder - A tract-based spatial statistics study. J Affect Disord. 2016;203:281-91.

83. Olvet DM, Delaparte L, Yeh F-C, DeLorenzo C, McGrath PJ, Weissman MM, et al. A comprehensive examination of white matter tracts and connectometry in major depressive disorder. Depress Anxiety. 2016; 33(1):56-65.

84. Basser PJ, Pajevic S, Pierpaoli C, Duda J, Aldroubi A. In vivo fiber tractography using DT-MRI data. Magn Reson Med. 2000;44(4):625-32.

85. Catani M, Howard RJ, Pajevic S, Jones DK. Virtual in vivo interactive dissection of white matter fasciculi in the human brain. Neurolmage. 2002;17(1):77-94.

86. Knöchel C, Schmied C, Linden DEJ, Stäblein M, Prvulovic D, de A de Carvalho $L$, et al. White matter abnormalities in the fornix are linked to cognitive performance in SZ but not in BD disorder: An exploratory analysis with DTI deterministic tractography. J Affect Disord. 2016; 201:64-78.

87. Jin Thong JY, Du J, Ratnarajah N, Dong Y, Soon HW, Saini M, et al. Abnormalities of cortical thickness, subcortical shapes, and white matter integrity in subcortical vascular cognitive impairment: Morphological Abnormalities in Vascular Cognitive Impairmentc. Hum Brain Mapp. 2014;35(5):2320-32

88. Du J, Goh A, Qu A. Large deformation diffeomorphic metric mapping of orientation distribution functions. Inf Process Med Imaging Proc Conf. 2011;22:448-62.

89. Baykara E, Gesierich B, Adam R, Tuladhar AM, Biesbroek JM, Koek $\mathrm{HL}$, et al. A Novel Imaging Marker for Small Vessel Disease Based on Skeletonization of White Matter Tracts and Diffusion Histograms: Novel SVD Imaging Marker. Ann Neurol. 2016;80(4):581-92.

90. Wardlaw JM, Smith EE, Biessels GJ, Cordonnier C, Fazekas F, Frayne $R$, et al. Neuroimaging standards for research into small vessel disease and its contribution to ageing and neurodegeneration. Lancet Neurol. 2013;12(8):822-38.

91. Bozzali M, Franceschi M, Falini A, Pontesilli S, Cercignani M, Magnani $G$, et al. Quantification of tissue damage in AD using diffusion tensor and magnetization transfer MRI. Neurology. 2001;57(6):1135-7.

92. Li C-X, Herndon JG, Novembre FJ, Zhang X. A Longitudinal Magnetization Transfer Imaging Evaluation of Brain Injury in a Macaque Model of NeuroAIDS. AIDS Res Hum Retroviruses. 2015;31(3):335-41.

93. Spilt A, Goekoop R, Westendorp RGJ, Blauw GJ, de Craen AJM, van Buchem MA. Not all age-related white matter hyperintensities are the same: a magnetization transfer imaging study. AJNR Am J Neuroradiol. 2006;27(9):1964-8.

94. Seo SW, Lee J-M, Im K, Park J-S, Kim S-H, Kim ST, et al. Cortical thinning related to periventricular and deep white matter hyperintensities. Neurobiol Aging. 2012;33(7):1156-67.

95. Kee Hyung Park, Lee J-Y, Na DL, Seong Yoon Kim, Cheong H-K, So Young Moon, et al. Different Associations of Periventricular and Deep White Matter Lesions with Cognition, Neuropsychiatric Symptoms, and Daily Activities in Dementia. J Geriatr Psychiatry Neurol. 2011; 24(2):84-90.

96. Bombois S, Debette S, Delbeuck X, Bruandet A, Lepoittevin S, Delmaire $\mathrm{C}$, et al. Prevalence of subcortical vascular lesions and association with executive function in mild cognitive impairment subtypes. Stroke. 2007;38(9):2595-7.

97. lannucci G, Dichgans M, Rovaris M, Brüning R, Gasser T, Giacomotti L, et al. Correlations between clinical findings and magnetization transfer imaging metrics of tissue damage in individuals with cerebral autosomal dominant arteriopathy with subcortical infarcts and leukoencephalopathy. Stroke. 2001;32(3):643-8.

98. Health Quality Ontario. The Appropriate Use of Neuroimaging in the Diagnostic Work-Up of Dementia: An Evidence-Based Analysis. Ont Health Technol Assess Ser Internet. 2014;14(1):1-64.

99. Alves GS, O’Dwyer L, Jurcoane A, Oertel-Knöchel V, Knöchel C, Prvulovic D, et al. Different patterns of white matter degeneration using multiple diffusion indices and volumetric data in mild cognitive impairment and Alzheimer patients. PloS One. 2012;7(12):e52859.

100. Johnson KA, Gregas M, Becker JA, Kinnecom C, Salat DH, Moran EK, et al. Imaging of amyloid burden and distribution in cerebral amyloid angiopathy. Ann Neurol. 2007;62(3):229-34. 
101. van Dalen JW, Scuric EEM, van Veluw SJ, Caan MWA, Nederveen AJ, Biessels GJ, et al. Cortical microinfarcts detected in vivo on 3 Tesla MRI: clinical and radiological correlates. Stroke. 2015;46(1):255-7.

102. Gupta RK, Saksena S, Hasan KM, Agarwal A, Haris M, Pandey CM, et al. Focal Wallerian degeneration of the corpus callosum in large middle cerebral artery stroke: serial diffusion tensor imaging. J Magn Reson Imaging JMRI. 2006;24(3):549-55.

103. Thomalla G, Glauche V, Weiller C, Röther J. Time course of wallerian degeneration after ischaemic stroke revealed by diffusion tensor imaging J Neurol Neurosurg Psychiatry. 2005;76(2):266-8.

104. Lanna ME de O, Alves CEO, Sudo FK, Alves G, Valente L, Moreira DM, et al. Cognitive disconnective syndrome by single strategic strokes in vascular dementia. J Neurol Sci. 2012;322(1-2):176-83.

105. van der Holst HM, Tuladhar AM, van Norden AGW, de Laat KF, van Uden IWM, van Oudheusden LJB, et al. Microstructural integrity of the cingulum is related to verbal memory performance in elderly with cerebral small vessel disease. Neurolmage. 2013;65:416-23.

106. Rolland Y, Payoux P, Lauwers-Cances V, Voisin T, Esquerré JP, Vellas B. A SPECT study of wandering behavior in Alzheimer's disease. Int $J$ Geriatr Psychiatry. 2005;20(9):816-20.

107. Cavallari M, Moscufo N, Meier D, Skudlarski P, Pearlson GD, White WB, et al. Thalamic Fractional Anisotropy Predicts Accrual of Cerebral White Matter Damage in Older Subjects with Small-Vessel Disease. J Cereb Blood Flow Metab. 2014;34(8):1321-7.

108. Guerra A, Petrichella S, Vollero L, Ponzo D, Pasqualetti P, Määttä S, et al. Neurophysiological features of motor cortex excitability and plasticity in Subcortical Ischemic Vascular Dementia: A TMS mapping study. Clin Neurophysiol. 2015;126(5):906-13.

109. Jeong H-G, Kim BJ, Yang MH, Han M-K, Bae H-J. Neuroimaging Markers for Early Neurologic Deterioration in Single Small Subcortical Infarction. Stroke. 2015;46(3):687-91.

110. Garriga M, Milà M, Mir M, Al-Baradie R, Huertas S, Castejon C, et al. 123I-FP-CIT SPECT imaging in early diagnosis of dementia in patients with and without a vascular component. Front Syst Neurosci. 2015;9:99.

111. Lin L, Xue Y, Duan Q, Sun B, Lin H, Chen X, et al. Microstructural White Matter Abnormalities and Cognitive Dysfunction in Subcortical Ischemic Vascular Disease: an Atlas-Based Diffusion Tensor Analysis Study. J Mol Neurosci. 2015;56(2):363-70.

112. Ostojic J, Kozic D, Pavlovic A, Semnic M, Todorovic A, Petrovic K, et al. Hippocampal diffusion tensor imaging microstructural changes in vascular dementia. Acta Neurol Belg. 2015;115(4):557-62.

113. Wu X-P, Gao Y-J, Yang J-L, Xu M, Sun D-H. Quantitative measurement to evaluate morphological changes of the corpus callosum in patients with subcortical ischemic vascular dementia. Acta Radiol. 2015;56(2):214-8.

114. Mascalchi M, Pantoni L, Giannelli M, Valenti R, Bianchi A, Pracucci G, et al. Diffusion Tensor Imaging to Map Brain Microstructural Changes in CADASIL: Brain Microstructural Changes in CADASIL. J Neuroimaging. 2017;27(1):85-91.

115. Pasi M, Boulouis G, Fotiadis P, Auriel E, Charidimou A, Haley K, et al. Distribution of lacunes in cerebral amyloid angiopathy and hypertensive small vessel disease. Neurology. 2017;88(23):2162-8. 